\title{
Microvesicles derived from hypoxia/ reoxygenation-treated human umbilical vein endothelial cells promote apoptosis and oxidative stress in $\mathrm{H} 9 \mathrm{c} 2$ cardiomyocytes
}

\author{
Qi Zhang ${ }^{1 \dagger}$, Man Shang ${ }^{1 \dagger}$, Mengxiao Zhang ${ }^{1}$, Yao Wang ${ }^{1}$, Yan Chen ${ }^{1}$, Yanna Wu ${ }^{1}$, Minglin Liu ${ }^{2,3}$, Junqiu Song ${ }^{1 *}$ \\ and Yanxia Liu ${ }^{1 *}$
}

\begin{abstract}
Background: Vascular endothelial dysfunction is the closely related determinant of ischemic heart disease (IHD). Endothelial dysfunction and ischemia/reperfusion injury (IRI) have been associated with an increase in microvesicles (MVs) in vivo. However, the potential contribution of endothelial microvesicles (EMVs) to myocardial damage is unclear. Here we aimed to investigate the role of EMVs derived from hypoxia/reoxygenation (H/R) -treated human umbilical vein endothelial cells (HUVECs) on cultured H9c2 cardiomyocytes.

Results: H/R injury model was established to induce HUVECs to release H/R-EMVs. The H/R-EMVs from HUVECs were isolated from the conditioned culture medium and characterized. $\mathrm{H} 9 \mathrm{c} 2$ cardiomyocytes were then incubated with 10, 30, $60 \mathrm{\mu g} / \mathrm{mL} \mathrm{H} / \mathrm{R}$-EMVs for $6 \mathrm{~h}$. We found that H9c2 cells treated by H/R-EMVs exhibited reduced cell viability, increased cell apoptosis and reactive oxygen species (ROS) production. Moreover mechanism studies demonstrated that H/R-EMVs could induce the phosphorylation of p38 and JNK1/2 in H9c2 cells in a dosedependent manner. In addition, H/R-EMVs contained significantly higher level of ROS than EMVs generated from untreated HUVECS, which might be a direct source to trigger a cascade of myocardial damage.

Conclusion: We showed that EMVs released during H/R injury are pro-apoptotic, pro-oxidative and directly pathogenic to cardiomyocytes in vitro. EMVs carry ROS and they may impair myocardium by promoting apoptosis and oxidative stress. These findings provide new insights into the pathogenesis of IRI.
\end{abstract}

Keywords: Endothelial microvesicles, Oxidative stress, Apoptosis, H9c2 cardiomyocytes, Hypoxia/reoxygenation

\section{Background}

Ischemic heart disease (IHD) is the major cause of death worldwide. The pathological processes leading to IHD (including myocardial infarction, angina pectoris, or both) are very complicated and closely accompanied with ischemia/reperfusion injury (IRI) [1]. It is generally

\footnotetext{
* Correspondence: song_junqiu@126.com; liu_yanxia126@126.com

Qi Zhang and Man Shang are co-first authors.

${ }^{\dagger}$ Equal contributors

'Department of Pharmacology, School of Basic Medical Sciences, Tianjin Medical University, No. 22, Qixiangtai Road, Heping District, Tianjin 300070, People's Republic of China

Full list of author information is available at the end of the article
}

accepted that oxidative stress is responsible for the damage of IRI, which is often associated with vascular dysfunction [2]. The endothelial cells that line the inner layer of blood vessels form a vital and dynamic structure that is essential for vascular hemostatic balance. These cells appear to be particularly vulnerable to the deleterious effects of both hypoxia (ischemia) and reoxygenation (reperfusion) [3].

Microvesicles (MVs) are small vesicles of $0.1 \sim 1 \mu \mathrm{m}$ diameter released from stimulated or apoptotic cells, such as platelets, endothelial cells, lymphocytes, erythrocytes and even smooth muscle cells [4]. MVs contain a 
subset of cell surface proteins derived from the plasma membrane of the original cells, which allow them to function as messengers that mediate many biological processes $[5,6]$. In addition, MVs also carry various bioactive molecules, such as cytokines, RNA and DNA derived from their metrocyte, which can be transferred into target cells and mediate a series of biological effects [7-9]. Increased levels of circulating MVs have been suggested in acute coronary ischemia, myocardial infarction and other IHD, and MVs are likely contributing to endothelial dysfunction, leukocyte adhesion, platelet activation and obstruction of blood flow [10].

It has been reported that endothelial microvesicles (EMVs) may participate in inflammatory responses or angiogenesis, and propagate biological responses involved in haemostatic balance [11, 12]. Recent evidence suggests that EMVs may contribute to the oxidative injury and cell apoptosis in the course of IRI [13]. EMVs derived under pathological high glucose conditions induce adhesion protein expression in endothelial cells and subsequent monocyte adhesion in a NADPH oxidase-ROS-p38-dependent way [14]. Our group previously reported that MVs derived from hypoxia/reoxygenation-treated HUVECs impaired relaxation of rat thoracic aortic rings, and declined the production of NO and the expression of p-eNOS [15]. In this experiment, we established hypoxia/reoxygenation injury model to induce EMVs release in vitro and investigated its role on endothelial function of the aortic rings. However, the detailed mechanisms underlying EMVsmediated cardiac damage and its relation to oxidative stress are not clear. Here we demonstrated the pathogenic roles of H/R-EMVs: (i) to cause cardiomyocytes injury directly; (ii) to promote cardiomyocytes apoptosis; (iii) to generate ROS in cardiomyocytes.

\section{Methods}

\section{Cell culture}

Human umbilical vein endothelial cells (HUVECs, Human EA.hy926 endothelial cells, Cell bank of Chinese Academy of Sciences, Shanghai, China) and H9c2 cells (ATCC, Manassas, VA, USA) were cultured in DMEM (Hyclone, Logan, UT, USA) with $10 \%$ FBS (Gibco, CA, USA) under standard cell-culture conditions $\left(37^{\circ} \mathrm{C}, 5 \%\right.$ $\mathrm{CO}_{2}$ ). All procedures were performed in accordance with the Declaration of Helsinki of the World Medical Association and the research protocol was approved by Ethics Committee of Tianjin Medical University.

\section{H/R-EMVs preparation}

To generate endothelial microvesicles (EMVs), HUVECs were stimulated by hypoxia/reoxygenation $(H / R)$ as previously described [15]. HUVECs of passage 5-8 were used when 70-80\% confluent. Briefly, HUVECs were subjected to hypoxic buffer (in mM: $0.9 \mathrm{NaH}_{2} \mathrm{PO}_{4}, 6.0$
$\mathrm{NaHCO}_{3}, 1.0 \mathrm{CaCl}_{2}, 1.2 \mathrm{MgSO}_{4}, 20.0$ HEPES, $98.5 \mathrm{NaCl}$, $10.0 \mathrm{KCl}, 40.0$ sodium lactate, $\mathrm{pH} 6.2$ ) in a hypoxic chamber $\left(95 \% \mathrm{~N}_{2}\right.$ and $5 \% \mathrm{CO}_{2}$, Billups-Rothenberg, Del Mar, CA, USA) for $12 \mathrm{~h}$ and then reoxygenated under standard cell-culture conditions for $4 \mathrm{~h}$. Hypoxic buffer was collected in $15-\mathrm{mL}$ centrifuge tubes and centrifuged at $2700 \mathrm{~g}, 4{ }^{\circ} \mathrm{C}$ for $20 \mathrm{~min}$ to remove cell debris. Most supernatants were collected in 13.2-mL ultracentrifuge tubes and centrifuged at $33000 \mathrm{rpm}$ for $150 \mathrm{~min}$ to pellet H/R-EMVs. The pellet was resuspended in $100 \mu \mathrm{L}$ PBS and kept at $-20{ }^{\circ} \mathrm{C}$.

\section{H/R-EMVs characterization by flow cytometry}

H/R-EMVs were characterized by flow cytometry in terms of size assessment and biomarker identification. After centrifuging at $2700 \mathrm{~g}, 4{ }^{\circ} \mathrm{C}$ for $20 \mathrm{~min}$, aliquots of $90 \mu \mathrm{L}$ supernatant without cell debris were collected and fixed with paraformaldehyde (PFA, Boster immunoleader, Wuhan, China) to a final concentration of $1 \%$ for $1 \mathrm{~h}$ at room temperature (RT), then snap-frozen in liquid nitrogen and stored at $-80{ }^{\circ} \mathrm{C}$. For flow cytometry analysis, $10 \mu \mathrm{L}$ fixed cell-free supernatants were blocked with mouse serum (Zhongkechenyu, Beijing, China) and then incubated with $5 \mu \mathrm{L}$ anti-PE-CD144 antibody or its anti-PE Mouse IgG1 isotype (Santa Cruz, CA, USA) in dark for $30 \mathrm{~min}$ at RT, respectively. Latex beads of $1 \mu \mathrm{m}$ (Molecular Probe, Invitrogen, Carlsbab, CA, USA) were used to calibrate gain setting and evaluate the size of EMVs. Events $<1 \mu \mathrm{m}$ in diameter and CD144 positive were defined as H/REMVs. Each sample was analyzed with the flow cytometer (FACS Calibur, BD biosciences, Franklin Lakes, NJ, USA). Protein quantification of $\mathrm{H} / \mathrm{R}$-EMVs was performed by a BCA protein assay (Beyotime, Nanjing, China).

\section{Treatment with H/R-EMVs on H9c2 cells}

H9c2 cells of passage 6-10 were used when $70-80 \%$ confluent. For subsequent experiments, H9c2 cells were incubated with 10, 30, $60 \mu \mathrm{g} / \mathrm{mL} \mathrm{H} / \mathrm{R}$-EMVs for $6 \mathrm{~h}$. After H/ R-EMVs treatment, culture supernatants and protein extracts of H9c2 cells were collected for further study.

\section{Colorimetric assay of cell viability and LDH activity}

Cell viability was determined using methyl thiazolyl tetrazolium (MTT, Amresco, Solon, OH, USA) method. H9c2 cells cultured in 96-well plates at $1 \times 10^{5}$ cells $/ \mathrm{mL}$ were treated with H/R-EMVs for $6 \mathrm{~h}$. Then they were incubated with $10 \mu \mathrm{L} 0.5 \%$ MTT solution for $4 \mathrm{~h}$ at $37^{\circ} \mathrm{C}$. The supernatant was discarded after the incubation and $150 \mu \mathrm{L}$ dimethyl sulfoxide was added to each well. The culture plate was shaken at high speed for $10 \mathrm{~min}$ until crystals dissolved completely. The absorbance of the blue formazan derivative was measured at a wavelength of $490 \mathrm{~nm}$ using a microplate reader (Bio-Rad Laboratories, CA, USA). 
Lactate dehydrogenase (LDH) release detection was performed using a LDH Kit (Jiancheng Bioengineering Institute, Nanjing, China). Culture supernatants of $\mathrm{H} 9 \mathrm{c} 2$ cells were collected after $6 \mathrm{~h}$ incubation with H/R-EMVs. Each supernatant $(20 \mu \mathrm{L})$ was transferred to a fresh 96well plate and an equal volume of freshly prepared reaction mixture was added according to the manufacturer's instruction. The absorbance was measured at a wavelength of $450 \mathrm{~nm}$ using the microplate reader following 15 min incubation at $37^{\circ} \mathrm{C}$. All experiments were repeated three times independently.

\section{H9c2 cell apoptosis assay}

Apoptosis of $\mathrm{H} 9 \mathrm{c} 2$ cells was examined by Hoechst 33258 staining, flow cytometry with Annexin V-FITC/PI staining and caspase 3 activity. After H/R-EMVs treatment, H9c2 cells in 6-well plates were washed twice with PBS and stained with $10 \mu \mathrm{g} / \mathrm{mL}$ Hoechst 33258 (KeyGen Biotech, Nanjing, China) at $37^{\circ} \mathrm{C}$ for $20 \mathrm{~min}$, and then examined under a fluorescent microscope (Nikon Melville, NY, USA) with the excitation wavelength of $350 \mathrm{~nm}$ for morphological changes.

To perform a quantitative analysis of cell apoptosis, flow cytometry with Annexin V-FITC/PI staining was employed. H9c2 cells were incubated with $5 \mu \mathrm{L}$ Annexin V-FITC and PI (BD biosciences, Franklin Lakes, NJ, USA) for 15 min at RT in dark. Cells from each sample were then analyzed by FacsCalibur flow cytometer. The data was analyzed using Flowjo software.

For detection of the activity of caspase 3, H9c2 cells in 6-well plates were trypsinized and collected, then lysed at $4{ }^{\circ} \mathrm{C}$ for $15 \mathrm{~min}$ in a caspase 3 lysis buffer (Beyotime, Nanjing, China). Protein extracts of $10 \mu \mathrm{L}$ were incubated with $90 \mu \mathrm{L}$ reaction buffer containing $2 \mathrm{mM}$ caspase-3 substrate (Ac-DEVD-pNA) for $2 \mathrm{~h}$ at $37{ }^{\circ} \mathrm{C}$. The absorbance was measured at a wavelength of $405 \mathrm{~nm}$ using a multilabel reader (Bio-Tek, Winooski, VT, USA). Results were expressed as $\mathrm{nmol} / \mu \mathrm{g}$ protein.

\section{Determination of lipid peroxidation level and superoxide dismutase activity}

Lipid peroxidation levels in $\mathrm{H} 9 \mathrm{c} 2$ cells were determined by estimating malondialdehvde (MDA) levels using the thiobarbituric acid reactive substance (TBARS) test (Jiancheng Bioengineering Institute, Nanjing, China). Cells were lysed by $1 \%$ Triton-X 100 for $30 \mathrm{~min}$ on ice and then centrifuged at $12000 \mathrm{~g}, 4{ }^{\circ} \mathrm{C}$ for $10 \mathrm{~min}$. Protein concentration of the supernatants was determined by the BCA protein assay. Aliquots of $30 \mu \mathrm{L}$ supernatants were incubated with reactive solutions according to the product instructions. The supernatant absorbance was measured at a wavelength of $532 \mathrm{~nm}$. The results were expressed as $\mathrm{nmol} / \mathrm{mg}$ protein.
The activity of superoxide dismutase (SOD) was measured in terms of inhibition of superoxide anions. Protein samples were prepared in the same way as MDA assay. Aliquots of $30 \mu \mathrm{L}$ supernatants were incubated with reactive solutions at $37^{\circ} \mathrm{C}$ water bath for $40 \mathrm{~min}$. The absorbance was measured at a wavelength of $550 \mathrm{~nm}$. SOD activities (U/mg protein) were calculated using the equation provided by the manufacture (Jiancheng Bioengineering Institute, Nanjing, China).

\section{Measurement of reactive oxygen species}

Both reactive oxygen species (ROS) content in H/R-EMVs and ROS production in $\mathrm{H} 9 \mathrm{c} 2$ cells were determined by $2^{\prime}, 7^{\prime}$-dichlorodihydrofluorescein diacetate assay (DCFHDA, Beyotime, Nanjing, China). Pelleted H/R-EMVs and adherent MVs-treated $\mathrm{H} 9 \mathrm{c} 2$ cells were diluted with $10 \mu \mathrm{M}$ DCFH-DA and incubated for $20 \mathrm{~min}$ at $37^{\circ} \mathrm{C}$ in dark, respectively. DCF intensity of MVs samples was analyzed with flow cytometry. To measure cellular ROS production, some MVs-treated H9c2 cells were washed and observed using fluorescent microscopy with the excitation wavelength of $520 \mathrm{~nm}$. The other MVs-treated H9c2 cells were washed, trypsinized, pelleted and resuspended with PBS at $1 \times 10^{6}$ cells $/ \mathrm{mL}$. DCF intensity of these cell samples was also measured using flow cytometry.

\section{Western blot analysis of Bcl-2/Bax, p-p38 and p-JNK1/2} H9c2 cells were lysed in a lysis buffer $(20 \mathrm{mM}$ Tris $\mathrm{pH}$ 7.5, $150 \mathrm{mM} \mathrm{NaCl}, 1 \%$ Triton X-100, sodium pyrophosphate, $\beta$-glycerophosphate, EDTA, $\mathrm{Na}_{3} \mathrm{VO}_{4}$, leupeptin, Beyotime, Nanjing, China) at $4{ }^{\circ} \mathrm{C}$ for $30 \mathrm{~min}$. Protein concentration was measured using BCA assay. Equal amounts of proteins $(80 \mu \mathrm{g})$ were loaded into $12 \%$ SDS electrophoresis and transferred onto PVDF membranes. Blots were incubated with blocking buffer for $60 \mathrm{~min}$ at RT, then incubated with the relevant primary antibodies (anti- $\beta$-actin, anti-Bcl-2, anti-Bax, antip-JNK1/2 antibody, Santa Cruz, CA, USA; anti-p-p38 MAPK, anti-p38 MAPK, anti-JNK1/2 antibody, Cell Signaling Technology, Danvers, MA, USA) overnight at $4{ }^{\circ} \mathrm{C}$, followed by the corresponding HRP-conjugated secondary antibodies for $120 \mathrm{~min}$. Then proteins were revealed by chemiluminescence using the ECL kit (Beyotime, Nanjing, China).

\section{Statistical analysis}

Data were expressed as mean \pm standard derivation (SD). The one-way analysis of variance (ANOVA) was used for multiple comparisons. Statistical evaluation was performed using GraphPad Prism 5. The value of $P<0.05$ was considered statistically significant. All experiments were repeated three times independently. 


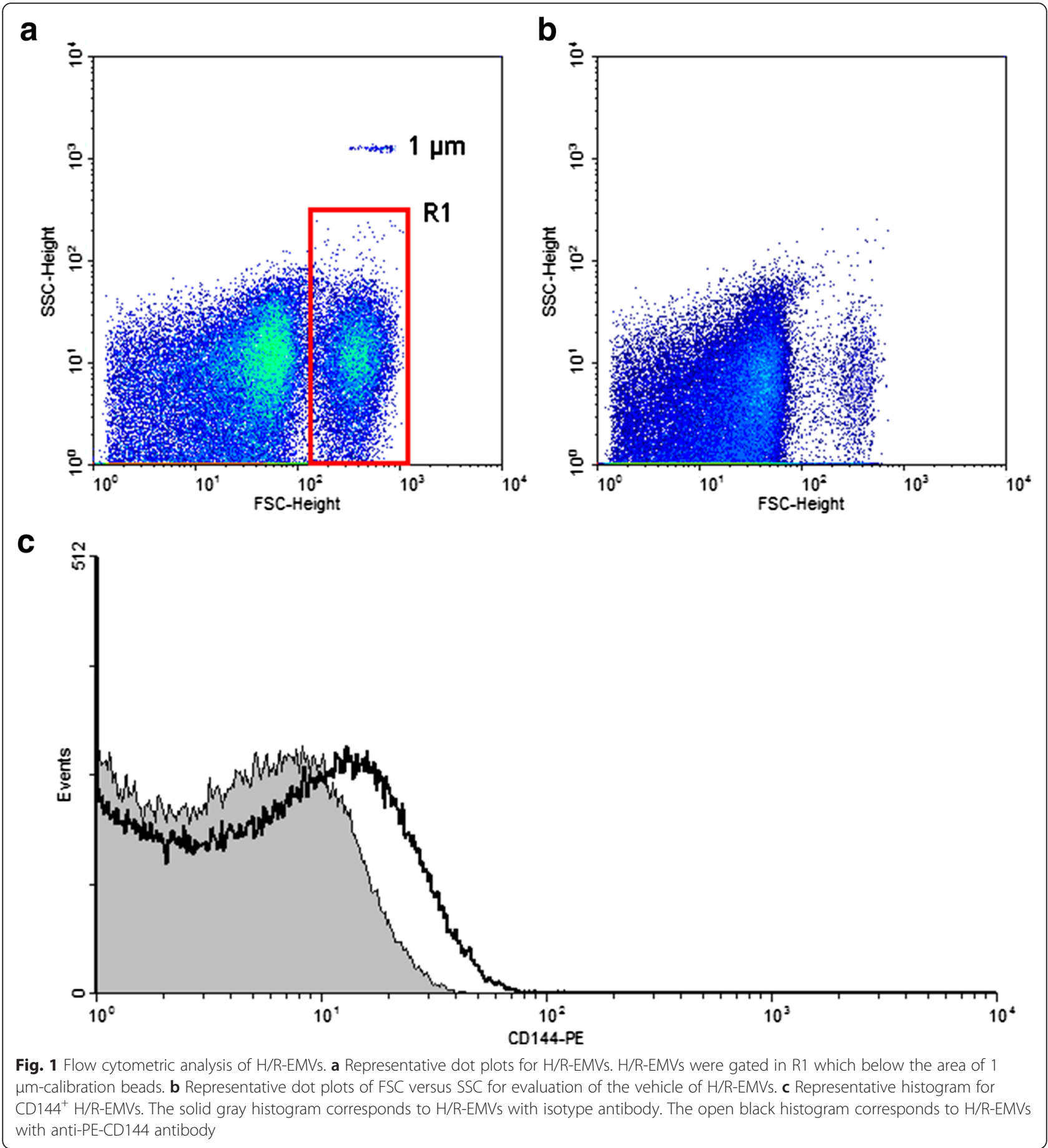

\section{Results}

\section{Characterization of H/R-EMVs}

H/R stimulation of HUVECs resulted in the formation of MVs of about $<1 \mu \mathrm{m}$ in diameter as assessed by flow cytometry. HUVECs were first exposed to hypoxia (12 h) and reoxygenation $(4 \mathrm{~h})$. The H/R injury decreased HUVECs viability to $70.53 \pm 2.61 \%$ compared with control $(P<$ 0.001 , supplemental data). Flow cytometry analysis of H/R-
EMVs was used to determine their size and cellular origin. Using $1 \mu \mathrm{m}$ beads as size standards, the majority of $\mathrm{H} / \mathrm{R}-$ EMVs were observed around the forward scatter signal corresponding to $1 \mu \mathrm{m}$ beads (Fig. 1a, b). Cellular origin was identified by investigating the specific surface antigens of MVs. Most of H/R-EMVs externalized their endothelial cell marker CD144 (Fig. 1c). These results indicated that H/REMVs had a size of $<1 \mu \mathrm{m}$ and expressed on their surface 

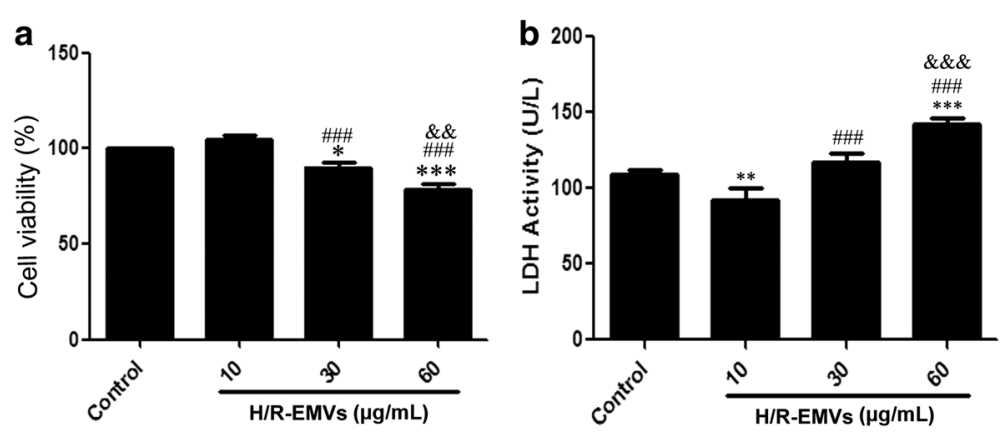

Fig. $2 \mathrm{H} / \mathrm{R}$-EMVs exerted cytotoxic effect on H9c2 cells. a MTT assays. H9c2 cells were treated with 10, 30,60 $\mu \mathrm{g} / \mathrm{mL}$ H/R-EMVs for 6 h. The viability of $\mathrm{H} 9 \mathrm{C} 2$ cells was expressed as a percentage relative to non-H/R-EMVs-treated control cells. Control cells were considered to be $100 \%$ viable. $\mathbf{b} \mathrm{LDH}$ activity assay. H9c2 cells were treated at the concentration of $10,30,60 \mu \mathrm{g} / \mathrm{mL} \mathrm{H} / \mathrm{R}$-EMVs for $6 \mathrm{~h}$ to detect LDH activity. ${ }^{*} p<0.05$, ${ }^{* * *} p<0.001$ versus control; $\# \#$ $p<0.001$ versus H/R-EMVs $10 \mu \mathrm{g} / \mathrm{mL} ;{ }^{\&} \& p<0.01$, \&\&\& $p<0.001$ versus H/R-EMVs $30 \mu \mathrm{g} / \mathrm{mL}$

adhesion molecules of HUVECs from which they originated.

\section{$\mathrm{H} / \mathrm{R}$-EMVs reduced the viability of $\mathrm{H} 9 \mathrm{c} 2$ cells}

To explore whether H/R-EMVs influence the progression of myocardium damage, target H9c2 cardiomyocytes were exposed to $10,30,60 \mu \mathrm{g} / \mathrm{mL} \mathrm{H} / \mathrm{R}$-EMVs for $6 \mathrm{~h}$, respectively. Compared with control group, $10 \mu \mathrm{g} /$ $\mathrm{mL} \mathrm{H} / \mathrm{R}-\mathrm{EMVs}$ showed little effect on H9c2 cells, whereas 30 and $60 \mu \mathrm{g} / \mathrm{mL} \mathrm{H} / \mathrm{R}$-EMVs significantly decreased $\mathrm{H} 9 \mathrm{c} 2$ cell viability by $10 \%$ and $20 \%$, respectively $(P<0.05$, Fig. 2a). The cytotoxic effect of H/REMVs was further confirmed using LDH assay. H/REMVs of $10 \mu \mathrm{g} / \mathrm{mL}$ did not induce more LDH leakage than the control group. As expected, H9c2 cells exposed to 30 and $60 \mu \mathrm{g} / \mathrm{mL} \mathrm{H/R-EMVs} \mathrm{exhibited} \mathrm{more} \mathrm{release}$ of LDH through damaged cell membranes $(P<0.05$, Fig. 2b). These findings indicated that H/R-EMVs displayed a dose-dependent cytotoxicity in H9c2 cardiomyocytes.

\section{H/R-EMVs increased H9c2 cell apoptosis}

In order to investigate the mechanisms of H/R-EMVs-induced cell death, we performed Hoechst 33258 staining and Annexin V-FITC/PI staining. After being treated with H/R-EMVs for $6 \mathrm{~h}, \mathrm{H} 9 \mathrm{c} 2$ cells were stained with Hoechst 33258 and observed under the fluorescence microscope. The dye stains condense chromatin of apoptotic cells more brightly than that of normal cells. H/R-EMVs groups in the concentrations of 10 and $30 \mu \mathrm{g} / \mathrm{mL}$ showed few fragmented nuclei, while $60 \mu \mathrm{g} /$ $\mathrm{mL} \mathrm{H} / \mathrm{R}-\mathrm{EMV}$ s group displayed apparently increasing number of fragmented or condensed nuclei (Fig. 3a). Flow cytometry with Annexin V-FITC/PI staining showed $60 \mu \mathrm{g} / \mathrm{mL} \mathrm{H} / \mathrm{R}$-EMVs increased the apoptotic rate of target H9c2 cells by $18 \%(P<0.05$, Fig. 3b, c).

To confirm the co-incubation of H9c2 cells with high dose of H/R-EMVs is contributable to their apoptosis, the activity of caspase 3 and expression of Bcl-2/Bax in target cells were determined. Consistent with the rates of Annexin $\mathrm{V}$ positive cells, caspase 3 activity of $\mathrm{H} 9 \mathrm{c} 2$ cells stimulated by $60 \mu \mathrm{g} / \mathrm{mL} \mathrm{H} / \mathrm{R}-\mathrm{EMVs}$ increased to $294.14 \pm 28.03 \mathrm{nmol} / \mu \mathrm{g}$, compared with $140.23 \pm 29.43$ $\mathrm{nmol} / \mu \mathrm{g}$ in control group $(P<0.05$, Fig. $3 \mathrm{~d})$. In addition, high dose $(60 \mu \mathrm{g} / \mathrm{mL})$ of $\mathrm{H} / \mathrm{R}$-EMVs also induced higher activity of caspase 3 than 10 and $30 \mu \mathrm{g} / \mathrm{mL} \mathrm{H} / \mathrm{R}$-EMVs $(P<0.05$, Fig. $3 \mathrm{~d})$. The dynamic balance of Bcl-2 and Bax determines a cell's fate. Bax levels increase but Bcl-2 levels decrease during cell apoptosis. Western blot analysis revealed that $\mathrm{Bcl}-2 / \mathrm{Bax}$ ratio in $\mathrm{H} 9 \mathrm{c} 2$ cells gradually decreased with the increasing dose of H/R-EMVs (Fig. 3e). Therefore, the pro-apoptotic effect of H/REMVs in H9c2 cells was associated with Bcl-2 inhibition and Bax up- regulation.

\section{$\mathrm{H} / \mathrm{R}$-EMVs induced the oxidative damage in $\mathrm{H} 9 \mathrm{c} 2$ cells by MDA and ROS production}

It has been reported that excessive generation of ROS plays a major role in the initiation of apoptosis during acute myocardial infarction. Specific ROS such as $\mathrm{H}_{2} \mathrm{O}_{2}$ or superoxide have been implicated as crucial mediators of apoptotic cell death [16]. As mentioned above, H/REMVs were confirmed to be pro-apoptotic, next we investigated whether H/R-EMVs induce excessive production of lipid peroxidation and ROS in target cardiomyocytes. Results showed that SOD (an eliminator of free radicals) activity of $\mathrm{H} 9 \mathrm{c} 2$ cells decreased, while MDA (an indicator of lipid peroxidation) content increased markedly in $60 \mu \mathrm{g} / \mathrm{mL} \mathrm{H} / \mathrm{R}$-EMVs-treated group when compared with control $(P<0.01$, Fig. $4 \mathrm{a}, \mathrm{b})$. In further experiments, ROS production was examined by fluorescent microscopy and flow cytometry in DCFHDA-labelled H9c2 cardiomyocytes. It was observed that ROS gradually accumulated in $\mathrm{H} 9 \mathrm{c} 2$ cells with the increasing dose of H/R-EMVs (Fig. 4c). Flow cytometry analysis showed that DCF fluorescence (ROS level) in 


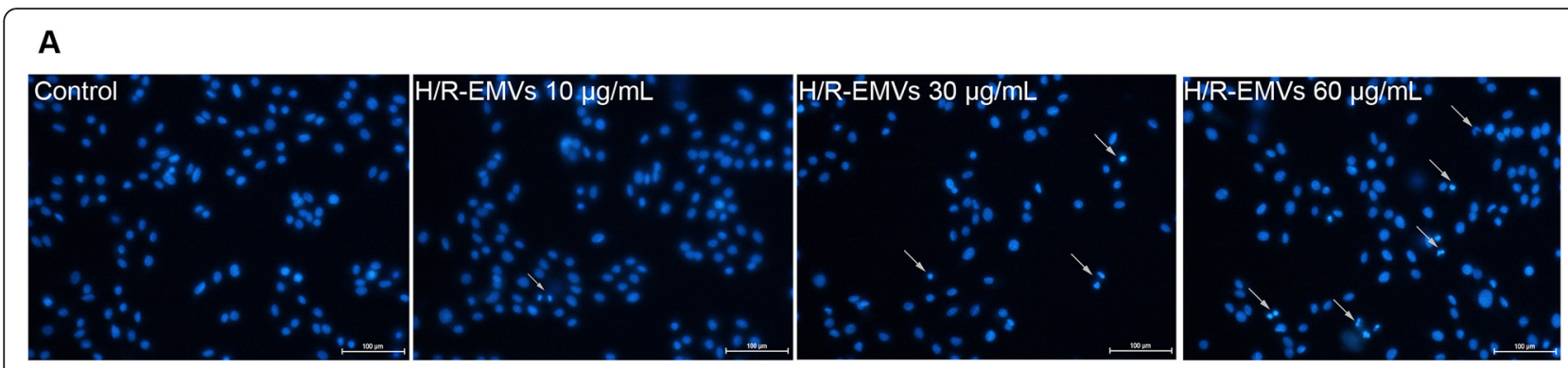

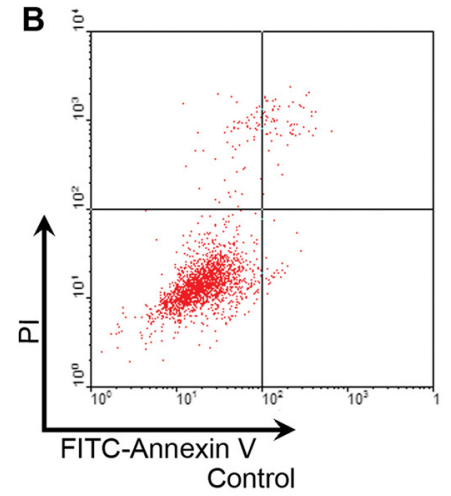

C

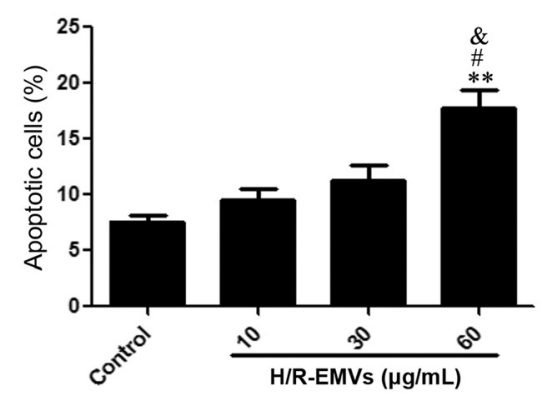

D

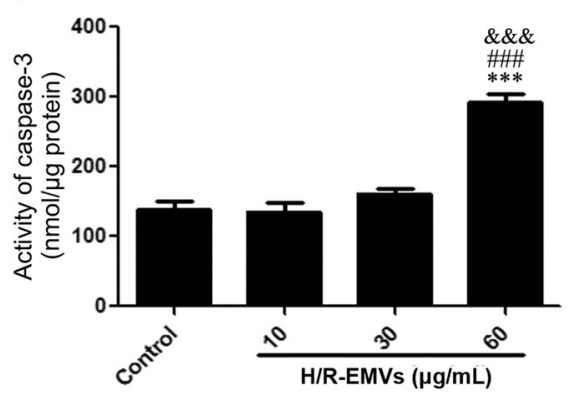

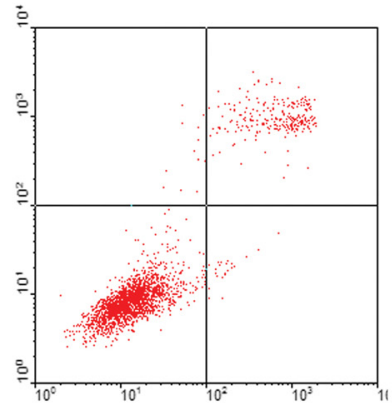

H/R-EMVs $30 \mu \mathrm{g} / \mathrm{mL}$

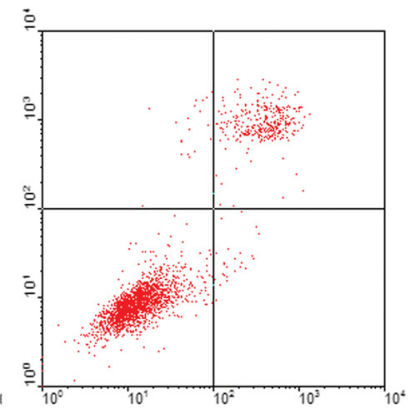

H/R-EMVs $60 \mu \mathrm{g} / \mathrm{mL}$
H/R-EMVs $10 \mu \mathrm{g} / \mathrm{mL}$
E
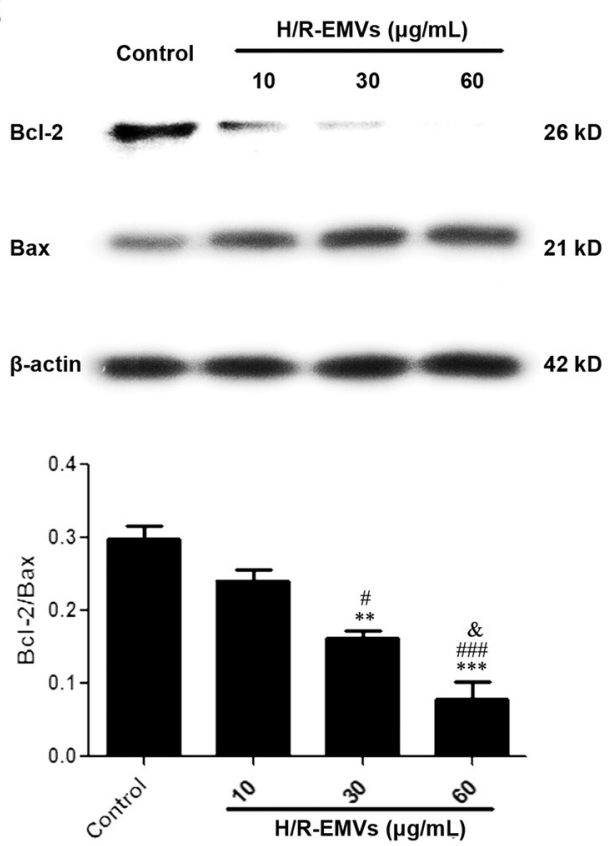

Fig. $3 \mathrm{H} / \mathrm{R}$-EMVs exhibited pro-apoptotic effect on H9c2 cells. a Hoechst 33258 staining was used to observe the apoptotic cells after treatment with 10, 30, $60 \mathrm{\mu g} / \mathrm{mL}$ H/R-EMVs for $6 \mathrm{~h}$ (100X). The arrows show apoptotic cells. The untreated cells serve as Control. b Annexin V-FITC/PI double staining. The results were interpreted in the following fashion: cells in the lower-left quadrant (Annexin $\mathrm{V}-/ \mathrm{PI}-$ ) represent living cells; those in the lower-right quadrant (Annexin $\mathrm{V}+/ \mathrm{PI}-$ ) represent early apoptotic cells; those in the upper-right quadrant (Annexin $\mathrm{V}+/ \mathrm{PI}+$ ) represent late apoptotic cells; and those in the upper-left quadrant (Annexin $\mathrm{V}-/ \mathrm{PI}+$ ) represent necrotic cells. $\mathbf{c}$ The apoptotic rate of H9c2 cells was quantified according to flow cytometry analysis. $\mathbf{d}$ Caspase 3 activity of H9c2 cells was measured after treatment with 10, 30, $60 \mu \mathrm{g} / \mathrm{mL} \mathrm{H} / \mathrm{R}$-EMVs for 6 h. e Representative images of immunoblots with antibodies against $\mathrm{BCl}-2, \mathrm{Bax}, \beta$-actin, respectively among groups. $\beta$-actin serves as a loading control. ${ }^{*} p<0.05,{ }^{* *} p<0.01$, ${ }^{* * *} p<0.001$ versus Control; ${ }^{*} p<0.05,{ }^{\# \#} p<0.01,{ }^{\# \# \#} p<0.001$ versus H/R-EMVs $10 \mu \mathrm{g} / \mathrm{mL}$; \& $p<0.05$, ${ }^{\text {\&\&\& }} p<0.001$ versus H/R-EMVs $30 \mu \mathrm{g} / \mathrm{mL}$ 


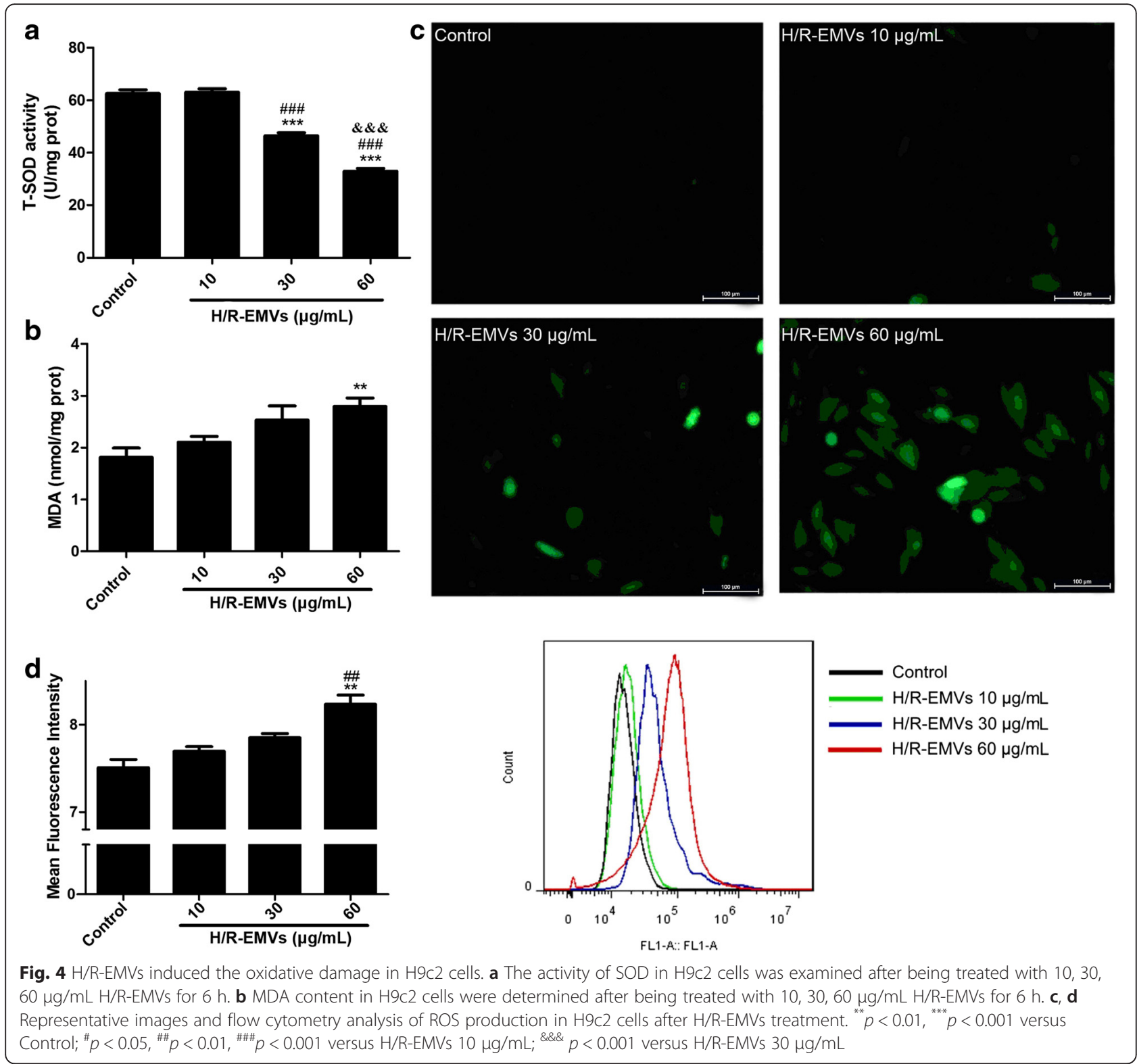

$60 \mu \mathrm{g} / \mathrm{mL} \mathrm{H} / \mathrm{R}$-EMVs-treated group increased by $9.59 \%$ compared with control $(P<0.01$, Fig. $4 d)$. These results suggested that H/R-EMVs trigger ROS production to induce target cell apoptosis and oxidative damage.

\section{H/R-EMVs up-regulated p-p38 MAPK and p-JNK1/2} expression in target $\mathrm{H} 9 \mathrm{c} 2$ cardiomyocytes

In this study, we performed Western blot analysis on p38 and JNK1/2 activation of target H9c2 cells. The activation of p38 MAPK pathway was indicated by a significant increase of p38 phosphorylation in $\mathrm{H} 9 \mathrm{c} 2$ cardiomyocytes treated with 30 or $60 \mu \mathrm{g} / \mathrm{mL} \mathrm{H} / \mathrm{R}$-EMVs $(P<0.01$, Fig. 5a). Moreover, the phosphorylation of JNK1/2 in H9c2 cells was up-regulated significantly in 30 and $60 \mu \mathrm{g} / \mathrm{mL} \mathrm{H} / \mathrm{R}-\mathrm{EMVs}$ groups compared with control $(P<0.01$, Fig. 5b). And the levels of p-p38 and $\mathrm{p}-J \mathrm{NK} 1 / 2$ were increased in target cells in a dosedependent manner. Thus, these findings showed that exposure of H9c2 cardiomyocytes to high dose H/R-EMVs results in activation of both the p38 and JNK1/2 signaling pathways.

\section{H/R-EMVs carried ROS}

To determine which factor in H/R-EMVs might be responsible for $\mathrm{p} 38$ and JNK1/2 activation in H9c2 cardiomyocytes, we assessed ROS content in H/R-EMVs. EMVs derived from normal cultured HUVECs (without hypoxia12 h/reoxygenation $4 \mathrm{~h}$ ) were introduced as control, which was defined as C-EMVs. Flow cytometry analysis showed that the DCF intensity of H/R-EMVs was 

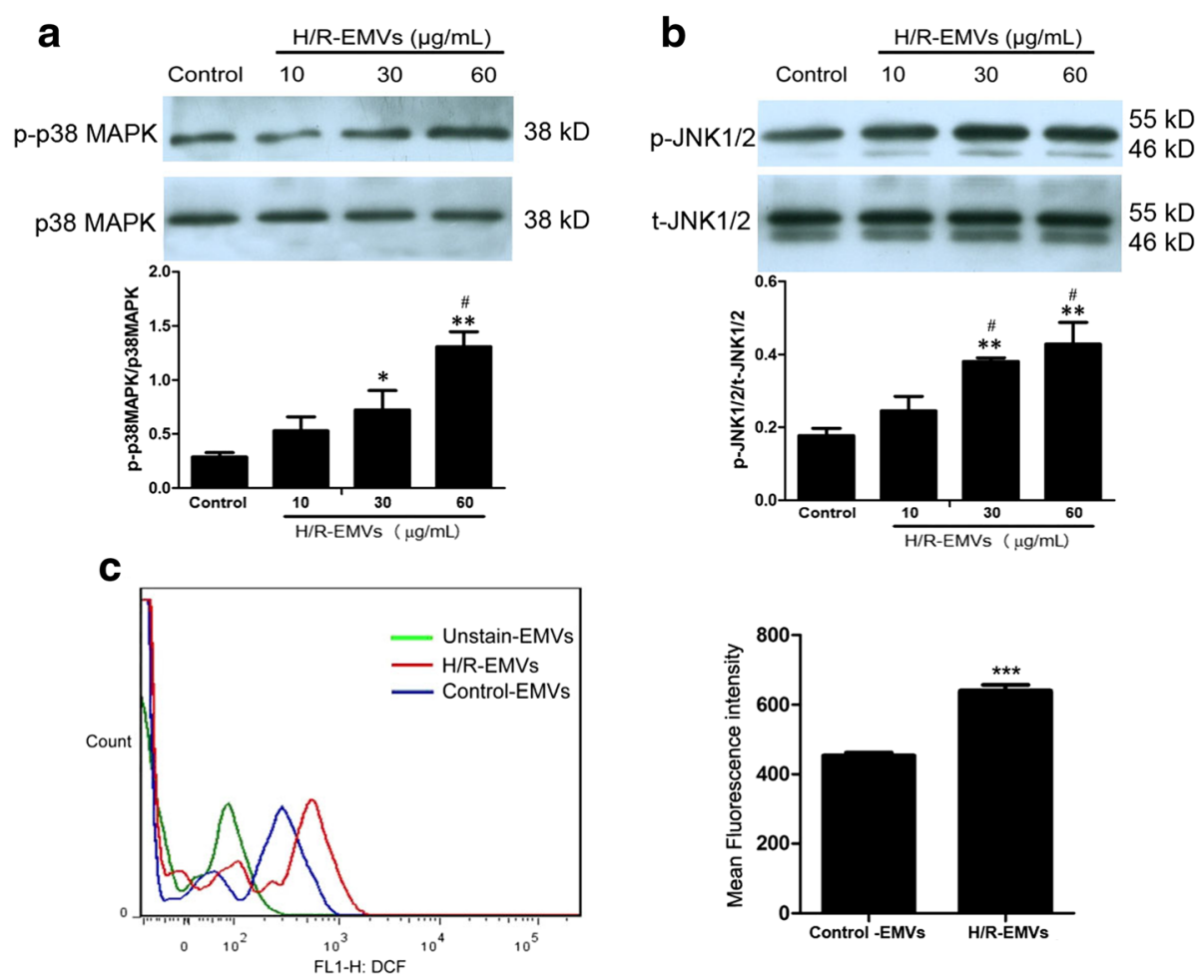

Fig. $5 \mathrm{H} / \mathrm{R}$-EMVs up-regulated the expression of p38 MAPK and JNK1/2 in H9c2 cells. a Representative images of immunoblots of p38 MAPK activation in each group. b JNK1/2 activation in H9c2 cells (phospho-JNK1/2). ${ }^{*} p<0.05,{ }^{* *} p<0.01$ versus Control; ${ }^{\#} p<0.05$ versus H/R-EMVs $10 \mu \mathrm{g} / \mathrm{mL}$. c ROS content in Control-EMVs and H/R-EMVs. ${ }^{* * *} p<0.001$ versus Control-EMVs

significantly stronger than that of C-EMVs, which indicated that H/R-EMVs contained more ROS than C-EMVs $(639.83 \pm 41.03$ v.s $453.67 \pm 20.42, \quad P<0.001$, Fig. 5 c) . Therefore, H/R-treated HUVECs released EMVs containing ROS. The ROS-containing EMVs might contribute to ROS production and subsequent oxidative stress in $\mathrm{H} 9 \mathrm{c} 2$ cells.

\section{Discussion}

IHD is a fatal disease and characterized by deficiency of coronary blood supply and impaired myocardium. MVs from various cellular origins have been identified in IHD, specially, EMVs account for a large proportion [17]. Accumulating evidences demonstrate that the elevated EMVs can actively modulate disease progression mostly including atherosclerosis and myocardial infarction [11]. EMVs could be interpreted as a vascular injury marker with prognostic value [18]. However, it is technically difficult to separate MVs from different origins in circulating blood. MVs are present at relatively low concentrations in normal physiological condition, but their levels increase in pathophysiological states $[19,20]$. Recent evidences showed that MVs could be generated abundantly from cells undergoing inflammation, radiation, oxidative stress and so on [6]. We have reported that EMVs could be generated from cultured endothelial cells by calcium ionophore A23187 in the manner of magnificent calcium influx [21]. As reperfusion therapy plays a critical role in the treatment of IHD, further exploration on the mechanism of IRI is very necessary. In our research, treatments of HUVECs by $H / R$ in vitro were used as a new approach to mimic IRI in vivo to generate EMVs. And flow cytometry analysis confirmed that the vesicles induced by H/R injury were EMVs with CD144 positive. However, MVs generated in normal physiological condition were hard to detect. Therefore, H/R-EMVs in different doses were used for functional studies.

Endothelial dysfunction is involved in the initial and core processes of the pathogenesis of IHD [22]. EMVs, released in response to endothelial cell activation or apoptosis, are significantly increased in patients with IHD, but their potential effect on myocardium is largely unknown. It has been reported that the level of EMVs among patients with myocardial infarction was positively correlated with the extent of vascular inflammation and myocardial infarct size [23]. EMVs generated from starved endothelial cells could dose-dependently suppress the endothelial cell proliferation with the dosage of $10^{3}-10^{5} \mathrm{EMVs} / \mathrm{mL}$ [24]. Interestingly our results showed that high concentrations of H/R-EMVs could significantly promote cell apoptosis. 
Cardiomyocyte apoptosis is a major event in the pathogenesis of IRI. Preliminary experiments indicated that in vivo myocardial $\mathrm{I} / \mathrm{R}$ treatment produced obvious myocardial infarction, and TUNEL staining showed many apoptotic myocytes in the ischemic area [25]. Apoptosis is caused by an imbalance between pro-apoptotic and antiapoptotic signals. It has already been known that Bax, $\mathrm{Bcl}-2$, and caspase-3 are downstream molecules in mitochondrial apoptotic signaling pathway [26]. In particular, activation of caspase-3 plays a central role in the initiation of apoptosis. In our study, we found that the expression ratio of $\mathrm{Bcl}-2 / \mathrm{Bax}$ in target cardiomyocytes was down- regulated by H/R-EMVs but the activity of caspase 3 was enhanced. These results confirmed the pro-apoptotic effects of H/R-EMVs on cardiomyocytes in vitro.

Specific ROS have been implicated as crucial mediators of apoptotic cell death. EMVs exposed to AT1-AA (Angiotensin II receptor type 1 autoantibody) or high glucose condition all greatly increased ROS production in target cells. These "injured" EMVs trigged oxidative stress and induced endothelial dysfunction [27]. In agreement with these studies, our research found that H/R-EMVs increased ROS production in terms of increasing MDA content and decreasing SOD activity in H9c2 cells.

Because of their potential relevance to cell apoptosis and oxidative damage, we aimed to determine the possible pathway in which H/R-EMVs may participate. Multiple mechanisms have been proposed to explain myocardial injury during IRI. ROS lead to cell damage either directly or through behaving as intermediates in p38 MAPK and JNK1/2 downstream signaling pathways [28]. As expected, our study found that p38 and JNK1/2 were activated after treatment of 30 or $60 \mu \mathrm{g} / \mathrm{mL} \mathrm{H} / \mathrm{R}$ EMVs. Additionally, it has been demonstrated that specific inhibition of p38 pathway resulted in reduced monocyte adhesion, in accordance with the downregulation of ICAM-1 and VCAM-1 in target cells [14]. The use of ROS inhibitors could abolish EMVs-induced ROS production and reduce $\mathrm{p} 38$ phosphorylation in target cells. Moreover, addition of "injured" MVs to primary hepatocytes induced up-regulation of pro-inflammatory COX- 2 and PKC- $\delta$ protein and the activation of JNK $1 / 2$ [13]. Taken together, these findings help us speculate that the activation of $\mathrm{p} 38$ and JNK1/2 could be triggered by ROS accumulation, suggesting that H/R- EMVs should probably promote oxidative stress in $\mathrm{H} 9 \mathrm{c} 2$ cardiomyocytes through p38 MAPK and JNK1/2 pathways.

IRI induces oxidative stress and intense inflammatory response resulting from the capacity of endogenous constituents. Recently, the bioactive contents carried by MVs are of great concerns. It has been discovered that MVs are not merely debris; they can carry cytokines and nuclear materials such as DNA, RNA, and microRNA from their metrocyte [7-9]. MVs from endothelial progenitor cells could transfer mRNA to endothelial cells and activate an angiogenic program [9]. Here, we found H/R-EMVs carry ROS with significantly high levels, indicating ROS content in H/R-EMVs might have a link with oxidative stress in target cells, as well as the increasing ROS production. However, the exact mechanism of the increased ROS production in target cells still needs further investigation.

\section{Conclusion}

In this study, we first established that EMVs could be generated from H/R-treated HUVECs. Then we demonstrated that $60 \mu \mathrm{g} / \mathrm{mL} \mathrm{H} / \mathrm{R}$-EMVs exerted pro-apoptotic and oxidative effects on $\mathrm{H} 9 \mathrm{c} 2$ cardiomyocytes via $\mathrm{p} 38$ and JNK1/2 signaling pathways. ROS carried by H/REMVs might be the underlying pathway to explicate their roles in apoptosis and oxidative stress. These findings indicated that the connection of EMVs and cardiomyocyte death would be interpreted as a novel intervention to study IRI, suggesting that decreasing the levels of EMVs should be a new therapeutic strategy for the maintenance of endothelial homeostasis and the treatment of IHD. However, whether other bioactive molecules in EMVs are contributable to myocardial injury is not clear. Moreover, our results need to be confirmed with the study of myocardial I/R models in vivo.

\section{Ethics}

All procedures were performed in accordance with the Declaration of Helsinki of the World Medical Association and the research protocol was approved by Ethics Committee of Tianjin Medical University.

\section{Consent}

All authors have read and approved the submission of this manuscript.

\section{Abbreviations \\ DCFH-DA: 2',7'-dichlorodihydrofluorescein diacetate; HUVECs: human umbilical vein endothelial cells; H/R: hypoxia/reoxygenation; IHD: ischemic heart disease; IRI: ischemia/reperfusion injury; LDH: lactate dehydrogenase; MDA: malondialdehvde; MTT: methyl thiazolyl tetrazolium; \\ MVs: microvesicles; PFA: paraformaldehyde; ROS: reactive oxygen species; RT: room temperature; SOD: superoxide dismutase; TBARS: thiobarbituric acid reactive substance.}

\section{Competing interests}

The authors declare that they have no competing interests.

\section{Authors' contributions}

Qi Zhang, Man Shang, Yanna Wu, Junqiu Song and Yanxia Liu: Study design; Qi Zhang and Man Shang: Directly participated in the performance of all the experiments; Mengxiao Zhang and Yao Wang: Establishing flow cytometry experiments; Yan Chen: Support on separation of MVs; Junqiu Song: Support on hypoxia/reoxygenation injury on HUVECs; Yanxia Liu and Minglin Liu:

Supervise during the whole work. All authors approved the final manuscript. 


\section{Acknowledgements}

This work was supported by the Specialized Research Fund for the Doctoral Program of Higher Education of China (No. 20101202110005), The National Natural Science Foundation of China (No. 81102446 and No. 81370422), the Natural Science Foundation of Tianjin (No. 11JCZDJC18300), the Research Foundation of Tianjin Municipal Education Commission (No. 20110106) and the National Key Basic Research Program of China (973 Program No. 2011CB933100).

\section{Author details}

'Department of Pharmacology, School of Basic Medical Sciences, Tianjin Medical University, No. 22, Qixiangtai Road, Heping District, Tianjin 300070, People's Republic of China. ${ }^{2}$ Section of Endocrinology, Department of Medicine, Temple University School of Medicine, 3500 North Broad Street, Room 480A, Philadelphia, PA 19140, USA. ${ }^{3}$ Department of Dermatology, Perelman School of Medicine, University of Pennsylvania, Philadelphia PA, 19104, USA

\section{Received: 2 December 2015 Accepted: 31 March 2016}

\section{Published online: 23 June 2016}

\section{References}

1. Ibanez B, Heusch G, Ovize M, Van de Werf F. Evolving therapies for myocardial ischemia/reperfusion injury. J Am Coll Cardiol. 2015;65(14):1454-71.

2. Mozaffari MS, Liu JY, Abebe W, Baban B. Mechanisms of load dependency of myocardial ischemia reperfusion injury. American journal of cardiovascular disease. 2013;3(4):180-96

3. Feng Y, Hu L, Xu Q, Yuan H, Ba L, He Y, Che H. Cytoprotective role of alpha1-antitrypsin in vascular endothelial cell under hypoxia/reoxygenation condition. J Cardiovasc Pharmacol. 2015:66(1):96-107.

4. Curtis AM, Edelberg J, Jonas R, Rogers WT, Moore JS, Syed W, Mohler ER, 3rd. Endothelial microparticles: sophisticated vesicles modulating vascular function. Vasc Med. 2013;18(4):204-14.

5. Laresche C, Pelletier F, Garnache-Ottou F, Lihoreau T, Biichle S, Mourey G, Saas P, Humbert P, Seilles E, Aubin F. Increased levels of circulating microparticles are associated with increased procoagulant activity in patients with cutaneous malignant melanoma. J Invest Dermatol. 2014; 134(1):176-82.

6. Leroyer AS, Anfosso F, Lacroix R, Sabatier F, Simoncini S, Njock SM, Jourde N, Brunet P, Camoin-Jau L, Sampol J et al. Endothelial-derived microparticles: Biological conveyors at the crossroad of inflammation, thrombosis and angiogenesis. Thromb Haemost. 2010;104(3):456-63.

7. Jansen F, Yang X, Hoelscher M, Cattelan A, Schmitz T, Proebsting S, Wenzel D, Vosen S, Franklin BS, Fleischmann BK, et al. Endothelial microparticlemediated transfer of MicroRNA-126 promotes vascular endothelial cell repair via SPRED1 and is abrogated in glucose-damaged endothelial microparticles. Circulation. 2013;128(18):2026-38.

8. Lannan KL, Sahler J, Kim N, Spinelli SL, Maggirwar SB, Garraud O, Cognasse F, Blumberg N, Phipps RP. Breaking the mold: transcription factors in the anucleate platelet and platelet-derived microparticles. Frontiers in immunology. 2015:6(48):1-16.

9. Deregibus MC, Cantaluppi V, Calogero R, Lo lacono M, Tetta C, Biancone L, Bruno S, Bussolati B, Camussi G. Endothelial progenitor cell derived microvesicles activate an angiogenic program in endothelial cells by a horizontal transfer of mRNA. Blood. 2007:110(7):2440-8.

10. Montoro-Garcia S, Shantsila E, Tapp LD, Lopez-Cuenca A, Romero Al, Hernandez-Romero D, Orenes-Pinero E, Manzano-Fernandez S, Valdes M, Marin F, et al. Small-size circulating microparticles in acute coronary syndromes: relevance to fibrinolytic status, reparative markers and outcomes. Atherosclerosis. 2013;227(2):313-22.

11. Zhang J, Ren J, Chen H, Geng Q. Inflammation induced-endothelial cells release angiogenesis associated-microRNAs into circulation by microparticles. Chin Med J (Engl). 2014;127(12):2212-7.

12. Arderiu G, Peña E, Badimon L. Angiogenic Microvascular Endothelial Cells Release Microparticles Rich in Tissue Factor That Promotes Postischemic Collateral Vessel Formation. Arterioscler Thromb Vasc Biol. 2015;35(2):348-57.

13. Teoh NC, Ajamieh H, Wong HJ, Croft K, Mori T, Allison AC, Farrell GC. Microparticles mediate hepatic ischemia-reperfusion injury and are the targets of Diannexin (ASP8597). PLoS One. 2014;9(9):e104376.

14. Jansen F, Yang X, Franklin BS, Hoelscher M, Schmitz T, Bedorf J, Nickenig G, Werner N. High glucose condition increases NADPH oxidase activity in endothelial microparticles that promote vascular inflammation. Cardiovasc Res. 2013;98(1):94-106.

15. Wang SX, Zhang Q, Shang M, Wei S, Liu M, Wang YL, Zhang MX, Wu YN, Liu ML, Song JQ, Liu YX. Microvesicles derived from hypoxia/reoxygenationtreated human umbilical vein endothelial cells impair relaxation of rat thoracic aortic rings. Zhongguo Ying Yong Sheng Li Xue Za Zhi. 2014;30(6):560-6.

16. Webster KA. Mitochondrial membrane permeabilization and cell death during myocardial infarction: roles of calcium and reactive oxygen species. Future Cardiol. 2012;8(6):863-84.

17. Shah MD, Bergeron AL, Dong JF, Lopez JA. Flow cytometric measurement of microparticles: pitfalls and protocol modifications. Platelets. 2008;19(5): 365-72.

18. Nozaki T, Sugiyama S, Koga H, Sugamura K, Ohba K, Matsuzawa Y, Sumida $H$, Matsui K, Jinnouchi H, Ogawa H. Significance of a multiple biomarkers strategy including endothelial dysfunction to improve risk stratification for cardiovascular events in patients at high risk for coronary heart disease. J Am Coll Cardiol. 2009;54(7):601-8.

19. Ou ZJ, Chang FJ, Luo D, Liao XL, Wang ZP, Zhang X, Xu YQ, Ou SJ. Endothelium-derived microparticles inhibit angiogenesis in the heart and enhance the inhibitory effects of hypercholesterolemia on angiogenesis. Am J Physiology-endocrinology Metabolism. 2011;300(4):E661-8.

20. Combes V, Simon A-C, Grau G-E, Arnoux D, Camoin L, Sabatier F, Mutin M, Sanmarco M, Sampol J, Dignat-George F. In vitro generation of endothelial microparticles and possible prothrombotic activity in patients with lupus anticoagulant. J Clin Investigation. 1999;104(1):93-102.

21. Shang $M$, Zhang $Q$, Zhang $M X$, Wang $Y$, Chen $Y$, Wu YN, Song JO, Liu ML, Liu YX. Effects of endothelial microvesicles induced by A23187 on H9c2 cardiomytes. Zhongguo Ying Yong Sheng Li Xue Za Zhi. 2013;6(29):559-64.

22. Eckers A, Haendeler J. Endothelial cells in health and disease. Antioxid Redox Signal. 2015;22(14):1209-11.

23. Radecke CE, Warrick AE, Singh GD, Rogers JH, Simon SI, Armstrong EJ. Coronary artery endothelial cells and microparticles increase expression of VCAM-1 in myocardial infarction. Thromb Haemost. 2014;113(3):605-16.

24. Mezentsev A, Merks RM, O'Riordan E, Chen J, Mendelev N, Goligorsky MS, Brodsky SV. Endothelial microparticles affect angiogenesis in vitro: role of oxidative stress. Am J Physiology-heart Circulatory Physiology. 2005;289(3): H1106-14.

25. Song JQ, Teng X, Cai Y, Tang CS, Qi YF. Activation of Akt/GSK-3beta signaling pathway is involved in intermedin(1-53) protection against myocardial apoptosis induced by ischemia/reperfusion. Apoptosis. 2009; 14(11):1299-307.

26. Jiang X, Guo CX, Zeng XJ, Li HH, Chen BX, Du FH. A soluble receptor for advanced glycation end-products inhibits myocardial apoptosis induced by ischemia/reperfusion via the JAK2/STAT3 pathway. Apoptosis. 2015;20(8): 1033-47.

27. Yang S, Zhong Q, Qiu Z, Chen X, Chen F, Mustafa K, Ding D, Zhou Y, Lin J, Yan $\mathrm{S}$, et al. Angiotensin II receptor type 1 autoantibodies promote endothelial microparticles formation through activating p38 MAPK pathway. J Hypertens. 2014;32(4):762-70.

28. Xiong XX, Liu JM, Qiu XY, Pan F, Yu SB, Chen XQ. Piperlongumine induces apoptotic and autophagic death of the primary myeloid leukemia cells from patients via activation of ROS-p38/JNK pathways. Acta Pharmacol Sin. 2015; 36(3):362-74.

\section{Submit your next manuscript to BioMed Central and we will help you at every step:}

- We accept pre-submission inquiries

- Our selector tool helps you to find the most relevant journal

- We provide round the clock customer support

- Convenient online submission

- Thorough peer review

- Inclusion in PubMed and all major indexing services

- Maximum visibility for your research

Submit your manuscript at www.biomedcentral.com/submit 